\title{
Erratum to: The Nature of Generalized Anxiety in Older Primary Care Patients: Preliminary Findings
}

\author{
Melinda A. Stanley • Gretchen J. Diefenbach • \\ Derek R. Hopko • Diane Novy • Mark E. Kunik • \\ Nancy Wilson $\cdot$ Paula Wagener
}

Published online: 3 March 2011

(C) Springer Science+Business Media, LLC 2011

\section{Erratum to: J Psychopathol Behav Assess (2003) 25:273-280 \\ DOI 10.1023/A:1025903214019}

On p. 278 of this article, there are errors in mean scores, standard deviations, t-test results, and specificity-sensitivity analyses for the abbreviated Penn State Worry Questionnaire (PSWQ-A) in older primary care patients with generalized anxiety disorder (PC-GAD) and those without any diagnosis (No DX). The corrected text, beginning on p. 277, is as follows:

The online version of the original article can be found at http://dx.doi. org/10.1023/A:1025903214019.

M. A. Stanley $(\bowtie) \cdot$ M. E. Kunik $\cdot$ N. Wilson $\cdot$ P. Wagener

VA Houston HSR\&D Center of Excellence,

Michael E. DeBakey Veterans Affairs Medical Center,

Houston, TX, USA

e-mail: melinda.a.stanley@uth.tmc.edu

M. A. Stanley $\cdot$ M. E. Kunik

Veterans Affairs South Central Mental Illness Research,

Education and Clinical Center,

Houston, TX, USA

M. A. Stanley $\cdot$ M. E. Kunik $\cdot$ N. Wilson

Baylor College of Medicine,

Houston, TX, USA

G. J. Diefenbach

The Institute of Living,

Hartford, CT, USA

D. R. Hopko

Department of Psychology, University of Tennessee,

Knoxville, TN, USA

D. Novy

Department of Anesthesiology and Pain Medicine,

The University of Texas M. D. Anderson Cancer Center,

Houston, TX, USA
A t-test indicated that scores on the abbreviated PSWQ (PSWQ-A) differed significantly between the PC-GAD and No Dx groups, $\mathrm{PC}-\mathrm{GAD}=29.6, \mathrm{SD}=6.21 ; \mathrm{No} \mathrm{Dx}=18.0, \mathrm{SD}=$ $5.31 ; \mathrm{t}(30)=5.12, p<.001 ; \eta^{2}=.47$. A distribution of scores for this measure is included in Table III. These data suggest that a score of 23 may provide a useful cutoff for identifying GAD. Associated specificity was $80.0 \%$, sensitivity $81.8 \%$, PPV $90.8 \%$, and NPV $66.7 \%$.

We would also like to note that the range of scores on the full PSWQ is 16 to 80 rather than 0 to 80 as stated on p. 275 . 